\title{
PERUBAHAN RUANG PADA BANGUNAN RUMAH PANJAE SUKU DAYAK IBAN KALIMANTAN BARAT
}

\author{
Muammar Ardli Hafiid ${ }^{1}$, Antariksa², Abraham Mohammad Ridjal ${ }^{3}$ \\ Mahasiswa Jurusan Arsitektur Fakultas Teknik Universitas Brawijaya \\ Dosen Jurusan Arsitektur Fakultas Teknk Universitas Brawijaya \\ Email: $\underline{\text { mr.hafiid@gmail.com }}$
}

\begin{abstract}
ABSTRAK
Rumah Panjang (Rumah Panjae) Rumah Tradisional Masyarakat Suku Dayak Iban Kalimantan Barat, Rumah Panjang atau betang di kenal dalam bahasa Suku Dayak Iban dengan Rumah Panjae. Rumah Panjae Suku Dayak Iban ini dibina dari tiang-tiang kayu ulin panjang, Rumah Panjae mempunyai makna tersendiri yang dilatari oleh kepercayaan yang ada dalam adat dan budaya masyarakat setempat. Begitu pula pada perubahan bangunan Rumah Panjae yang mengalami perubahan karena kebutuhan dari masyarakat. Penelitian ini fokus pada permasalahan perubahan ruang pada bangunan Rumah Panjae Suku Dayak Iban Kalimantan Barat. Penelitian ini bertujuan untuk mengidentifikasi dan menganalisis perubahan ruang pada bangunan Rumah Panjae Suku Dayak Iban Sungai Utik Kalimantan Barat. Pelaksanaan penelitian menggunakan metode deskriptif, dengan survei langsung ke lapangan, yang mengamati perubahan ruang pada bangunan Rumah Panjae. Hasil studi menunjukkan bahwa perubahan ruang yang terjadi pada Rumah Panjae Suku Dayak Iban di pengaruhi oleh kebutuhan masyarakat saat ini, berupa dapur (Uji Bilik) dan ruang santai (Kaki Lima) terdapat pada bagiaan depan Rumah Panjae.
\end{abstract}

Kata kunci: Rumah Panjae, Perubahan Ruang

\begin{abstract}
Long House (Rumah Panjae) Traditional Home Society of West Kalimantan Dayak Iban, long house or betang know in Dayak Iban language as Rumah Panjae. Long House (Rumah Panjae). Panjae Dayak Iban house is constructed of ironwood poles long, Rumah Panjae has its own meaning is backed by the confidence that exists in the customs and culture of the local community. Similarly, the change in house building Panjae is changing due to the needs of society. This study focuses on the problems of space changes in house building Dayak Iban language as Rumah Panjae West Kalimantan. This study aims to identify and analyze changes in the building space Dayak Iban House Panjae Utik River West Kalimantan. Conducting research using descriptive method, the survey directly into the field, the observed changes in the building space Panjae house. The study shows that changes that occur in the House chamber Panjae Dayak Iban influenced by the needs of today's society, such as the kitchen (Uji Bilik) and lounge (Kaki Lima) contained in the house being brought forward Panjae.
\end{abstract}

Keyword: Rumah Panjae, Changes In Space

\section{Pendahuluan}

Desa Sungai Utik Kalimantan Barat sampai saat ini masih memiliki hutan adat yang masih terjaga karena keberadaan Rumah Panjae yang di huni oleh Suku Dayak 
Iban. Pemahaman Rumah Panjae dibidang arsitektur hanya dimengerti pada bagian lantai panggung dan bentuk memanjang, seperti dibeberapa bangunan kantor wilayah di Kalimantan Barat, sedangkan ruang - ruang pada Rumah Panjae juga memiliki arti dan makna serta nilai - nilai, adat istiadat dari Suku Dayak Iban yang hidup secara bersama agar dapat mengetahui keberadaan ruang bersama karena Rumah Panjae di huni banyak kepala keluarga. Rumah Panjae Suku Dayak Iban ini sudah beberapa kali mengalami perpindahan sekitar tahun 1830-an dan kemudian menetap di Kampung Sungai Utik pada tahun 1972 hingga sekarang, rumah yang panjangnya sekitar 170,65 meter saat ini di huni \pm 80 kepala keluarga. Rumah Panjae Suku Dayak Iban menjadi pusat kehidupan masyarakat Iban Sungai Utik dengan bentuk bangunan komunal yang unik memanjang mengikuti arus sungai.

\section{Bahan dan Metode}

\subsection{Arsitektur Rumah Panjae Suku Dayak Iban Sungai Utik}

Hakekat rumah dalam kehidupan manusia adalah sebagai pusat realisasi kehidupannya, pusat kegiatan budaya, tempat manusia berinteraksi dengan sesamanya, dalam lingkup keluarga atau masyarakat. Segi fisik, rumah sebagai wadah tempat tinggal berfungsi untuk mendapatkan perlindungan dan melakukan kegiatan sosial dalam keluarga maupun masyarakat. Interaksi antara rumah dan penghuni adalah apa yang diberikan rumah kepada penghuni, serta apa yang dilakukan penghuni terhadap rumahnya (Turner, 1972). Pengertian rumah (perumahan) dalam kaitan dengan proses menurut Silas [1983] adalah rumah atau perumahan sebagai suatu proses berkembang sesuai dengan kehendak, kemampuan dan peluang yang ada setiap saat sejalan dengan pertumbuhan/ perkembangan biologis, sosial dan ekonomi keluarga bersangkutan. Selanjutnya dikatakan bahwa perkembangan rumah adalah multi dimensi artinya. Rumah juga merupakan hasil dari kebudayaan, yaitu lebih tepatnya kepada hasil olah tangan dan akal pikiran manusia yang dipedomani oleh kebudayaan yang terwujud dalam bentuk bangunan fisik yang memiliki fungsi serta nilai-nilai tertentu [Triyanto, 2001].

Rumah Panjae ( Rumah Panjang ) berbentuk lantai panggung dengan ketinggian panggung sekitar $1.5 \mathrm{~m}$ merupakan rumah masyarakat Dayak Iban yang masih di tempati hingga saati ini. Rumah Panjae memang menjadi pusat kehidupan masyarakat Iban Sungai Utik yang hingga kini masih terjaga turun temurun dari generasi ke generasi, namun meskipun begitu rumah panjang ini terus menyesuaikan dengan zaman perlahan-lahan sehingga tidak tertinggal terlalu jauh, mengingat Rumah Panjae ini jauh dari perkotaan sehingga tidak terlalu terasa perubahan yang terjadi pada Rumah Panjang Suku Dayak Iban Sungai Utik.

Saat matahari mulai melihatkan diri setiap pagi hari adalah pagi yang sangat sibuk di Rumah Panjae Sungai Utik, suara langkah di lantai kayu Rumah Panjae menandai warga mulai beraktifitas. Anak-anak bersiap untuk pergi ke sekolah, para perempuan dan pria mulai siap pergi ke ladang, berburu atau melakukan kerja bakti. Sekitar pukul 09.00 pagi hari, maka Rumah Panjae mulai senyap. Namun beberapa nenek-nenek yang tidak pergi ke ladang biasanya sibuk menjemur padi, menganyam tikar, dan lain-lain. Setelah hingga siang hari, maka pada sore hari, Rumah Panjae mulai ramai kembali oleh suara anak-anak bermain, atau warga yang ngobrol di bagian Ruai. Di sore hari pula, mayoritas para pria 
biasanya berkumpul secara bergantian di bilik untuk menikmati minuman tuak atau saguer (minuman dari Pohon Enau) di bagian belakang atau dapur. Aktifitas minum bersama-sama ini disebut "ngasap" yang mengikat kebersamaan warga Rumah Panjae.

Rumah Panjae (rumah panjang) Suku Dayak Iban yang panjangnya sekitar 170,65 meter ini, terdiri dari 28 bilik yang dibagi dalam beberapa bagian, yaitu:

1. TANJU' berfungsi sebagai tempat menjemur hasil panen baik itu padi ataupun biasanya di gunakan untuk menjemur pakaian. Letak ruang Tanju' adalah di bagian depan Rumah Panjae. Ruang Tanju' merupakan ruang terbuka tanpa atap yang biasanya menjadi salah satu tempat awal mula kegiatan ritual tertentu di Rumah Panjae.

2. KAKI LIMA adalah ruang di sebelah ruang Tanju'. Kaki Lima adalah ruang tambahan baru dalam Rumah Panjae karena kebutuhan sehingga ada penambahan ruang pada bagian depan rumah setelah ruang tanju'. Ruang Kaki Lima berfungsi sebagai ruang sirkulasi dan sebagai tempat bermain bagi anak - anak. Lebar ruang Kaki Lima adalah sekitar $120 \mathrm{~cm}$. Ketinggian ruangan sekitar $250 \mathrm{~cm}$.

3. RUAI berfungsi sebagai tempat berkumpul, bermusyawarah dan bersosialisasi bagi para penghuni Rumah Panjang. Ruai juga berfungsi sebagai tempat menerima tamu dan melangsungkan ritual upacara adat seperti upacara melahirkan, kematian atau lainnya.

4. SADAU RUAI merupakan plafon bagian luar. Sadau Ruai berfungsi sebagai tempat untuk menyimpan tikar dan peralatan menangkap ikan.

5. BILIK merupakan ruang bagian dalam yang berfungsi sebagai tempat tidur bagi para penghuni Rumah Panjae. Bilik juga berfungsi sebagai tempat untuk menyimpan barang-barang pusaka seperti gong, guci, dan barang-barang pusaka lainnya. Dahulu bilik dan dapur dijadikan satu, tetapi sekarang ada ruang Uji Bilik dipisah agar tidak kena asap dan lebih sehat bagi penghuninya. Hingga sekarang ruang tersebut berfungsi sebagai area servis saat ini sebagai pelataran dari ruang dapur masing masing bilik.

6. SADAU letaknya di atas bilik yang berfungsi untuk menaruh padi.

7. SADAU BUGAU Sadau letaknya di atas sadau bilik yang berfungsi sebagai tempat menyimpan tikar atau hasil kerajianan, peralatan pertanian yang jarang digunakan.

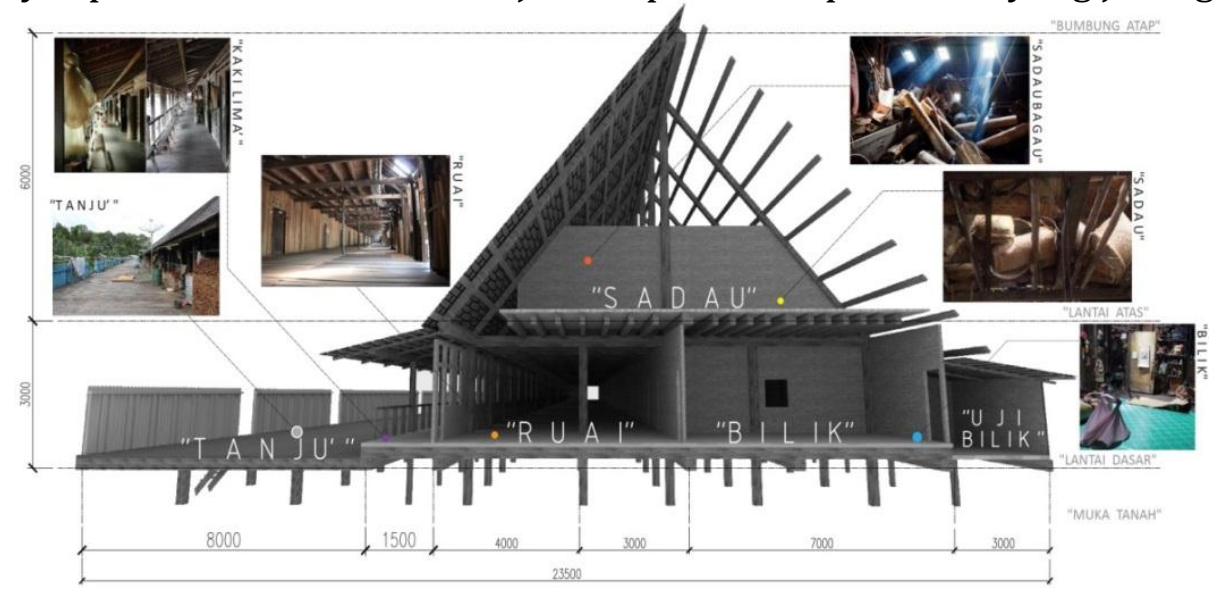

Gambar 1. Ruang - ruang pada Rumah Panjae Suku Dayak Iban. 


\subsection{Metode Penelitian}

Penelitian tentang perubahan ruang pada bangunan Rumah Panjae ini, dilakukan dengan mengamati perubahan ruang dalam bangunan melewati gambar denah, observasi langsung dan wawancara dengan penghuni rumah untuk mencari kembali informasiinformasi tentang rumah tersebut, dengan menggunakan metode survei deskriptif. Metode yang digunakan pada penelitian ini adalah deskriptif, menganalisis tentang arsitektur Rumah Panjae dari variabel berupa orientasi rumah, ruang dalam hingga kondisi ruang setelah mengalami penambahan ruang.

\section{Hasil dan Pembahasan}

3.1 Orientasi arah hadap Rumah Panjae Suku Dayak Iban Sungai Utik

Rumah Panjae Suku Dayak Iban Kalimantan Barat memiliki orientasi yang mempunyai arti tersendiri sesuai kepercayaan dari masyarakat Suku Dayak Iban. Rumah Panjae Suku Dayak Iban mereka memiliki orientasi:

1. Dibangun sejajar dengan sungai yang ada di depannya yang dianggap sebagai sumber kehidupannya sehari-hari;

2. Mengacu kepada pergerakan matahari dari timur (matahari tumboh) ke barat (matahari padam). Timur dimaknakan sebagai kehidupan dan barat sebagai kematian. Rumah dianggap sebagai cermin dari perjalanan matahari dari horison ke horison (tisau langit) dalam sebuah kosmos. Aplikasinya dalam bentuk rumah tinggal dan susunan ruang dalamnya menghasilkan teras rumah (tanju') yang disimbolkan sebagai matahari dan mendapatkan sinar matahari secara penuh sebagai lambang kehidupan dan bagian dalam rumah yang disimbolkan sebagai malam (gelap) yang melambangkan jiwa, Tuhan, dan semangat.

3. Rumah Panjae (Rumah Panjang) harus sejajar dengan sungai serta menghadap sungai dan tidak boleh melintang sungai. Ketika ada upacara adat posisi duduk harus menghadap ke matahari terbit.

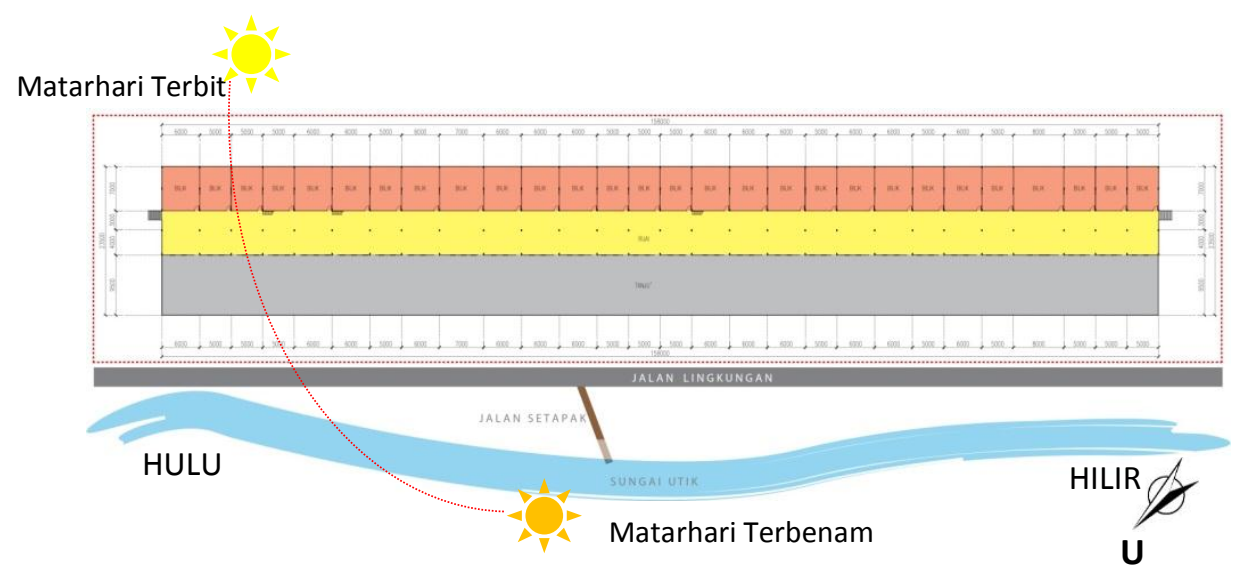

Gambar 2. Orientasi arah hadap Rumah Panjae berpola linier harus mengikuti sungai. 
4. Rumah Panjae (Rumah Panjang) setelah penambahan ruang tetap sejajar dengan sungai dan menghadap sungai, tidak terjadi perubahan pada orientasi.

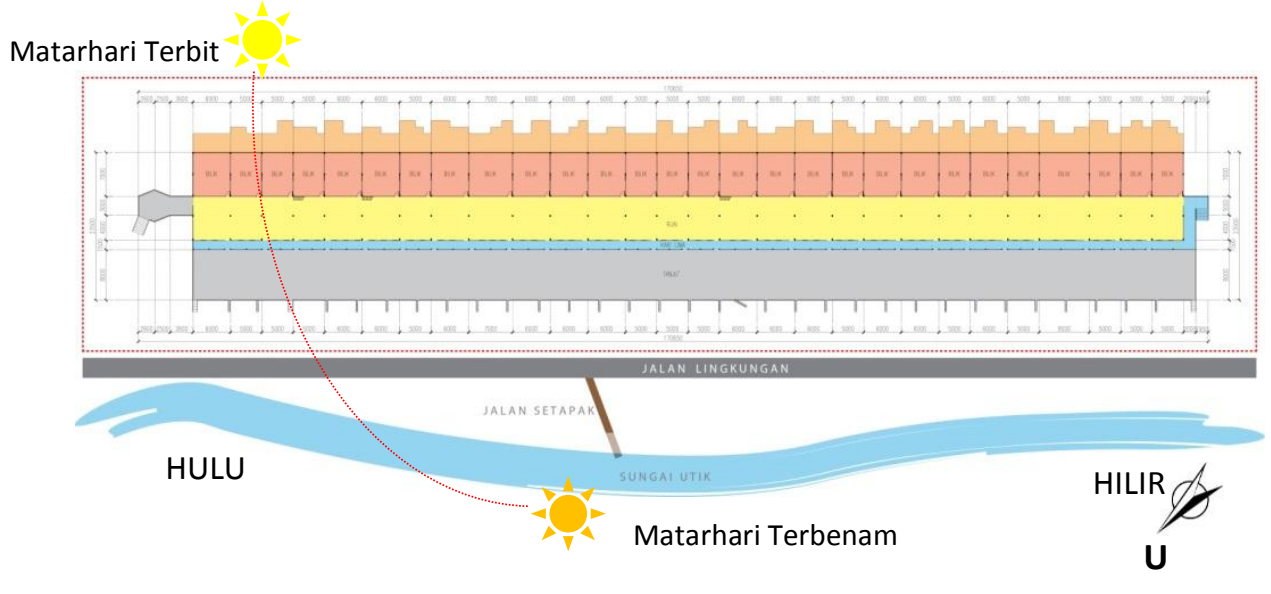

Gambar 3. Penambahan ruang Rumah Panjae tetap berpola linier mengikuti sungai.

Orientasi arah hadap bangunan Rumah Panjae (rumah panjang) di tandai dengan teras depan (tanju') memiliki arah penunjuk mata angin yaitu ke arah matahari terbenam Barat - Timur pada bagian belakang rumah atau ruang bilik dari Rumah Panjae (rumah panjang) seperti Gambar 4.4 diliat bahwa Rumah Panjae (rumah panjang) memiliki kepercayaan arus sungai yang mengarah ke Hulu dan ke Hilir karena mereka berasal dari Hilir (sumber kehidupan) dan mengarah ke Hulu.

\subsection{Ruang - ruang pada Rumah Panjae Suku Dayak Iban Sungai Utik}

Rumah Panjae selain memiliki bentuk yang sangat sederhana, bentuk juga mersepon iklim setempat dan dahulu juga sebagai pertahanan dari serangan musuh ketika perang antar suku yang sering terjadi. Ruang Rumah Panjae sangat sederhana karena berfungsi sesuai kebutuhan saat itu, baik itu untuk menjemur hasil pertanian dan berkumpul, istirahat dan berkegiatan sehari - hari serta atas dasar kepercayaan masyarakat dari para leluhur mereka, terkadang di gunakan juga untuk ritual upacara adat tertentu, zona ruang yang terdapat didalam Rumah Panjae dilakukan berdasarkan pengelompokan kepercayaan akan orientasi matahari yang berarti pada bagian timur adalah kehidupan pada ruang bilik sedangkan pada ruang tanju' di arah barat yang berarti kematian. 

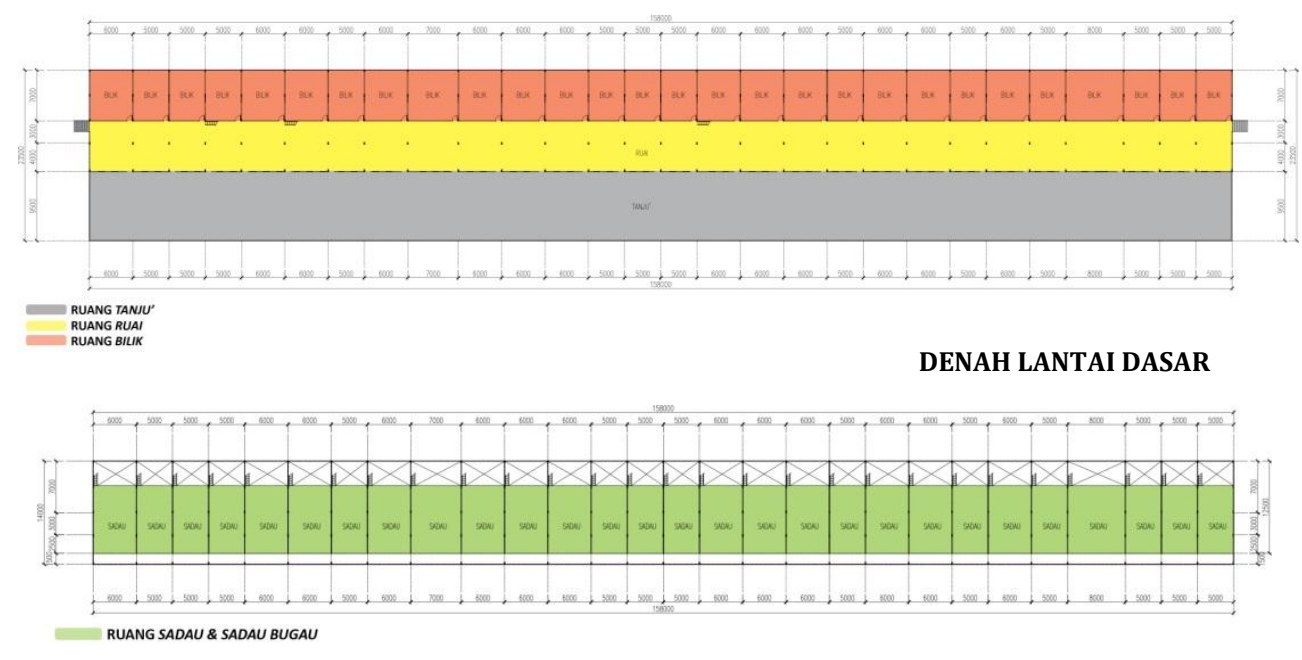

DENAH LANTAI ATAS/ATAP

Gambar 4. Denah Asli/Asal Rumah Panjae Suku Dayak Iban Sungai Utik

\subsection{Perubahan Ruang Rumah Panjae Suku Dayak Iban Sungai Utik}

Pada masa perkembangan dan seiring berjalannya waktu untuk menyesuaikan dengan kebutuhan masyarakat saat ini yang mau tidak mau mengikiti gaya hidup modern yang mempengaruhi beberapa penambahan ruang pada ruang Rumah Panjae namun penambahan ini juga sangat sederhana seperti Gambar yang menjelaskan bagaimana pengelompokan tersebut terjadi pada Gambar 4.4. Terdapat dua ruang penambahan pada rumah panjang, pertama pada bagian depan Ruai yang di beri nama ruang Kaki Lima ruang ini menjadi fungsi sirkulasi pada bagian depan Rumah Panjae tidak ada alasan tertentu kenapa di tambahkan fungsi ruang ini namun menurut penjelasan dari masyarakat ruang ini biasanya di gunakan untuk tempat berkumpul dan bermain anak - anak serta menyimpan peralatan pertanian di bagiaan atasnya. Penambahan ruang kedua terdapat di belakang ruang bilik hal ini juga berkaitan dengan kebutuhan, dan alasan seperti memisahkan dapur dari ruang bilik agar tidak kena asap dan lebih sehat bagi penghuninya. Hingga sekarang ruang tersebut berfungsi sebagai area servis saat ini sebagai pelataran dari ruang dapur masing - masing bilik.

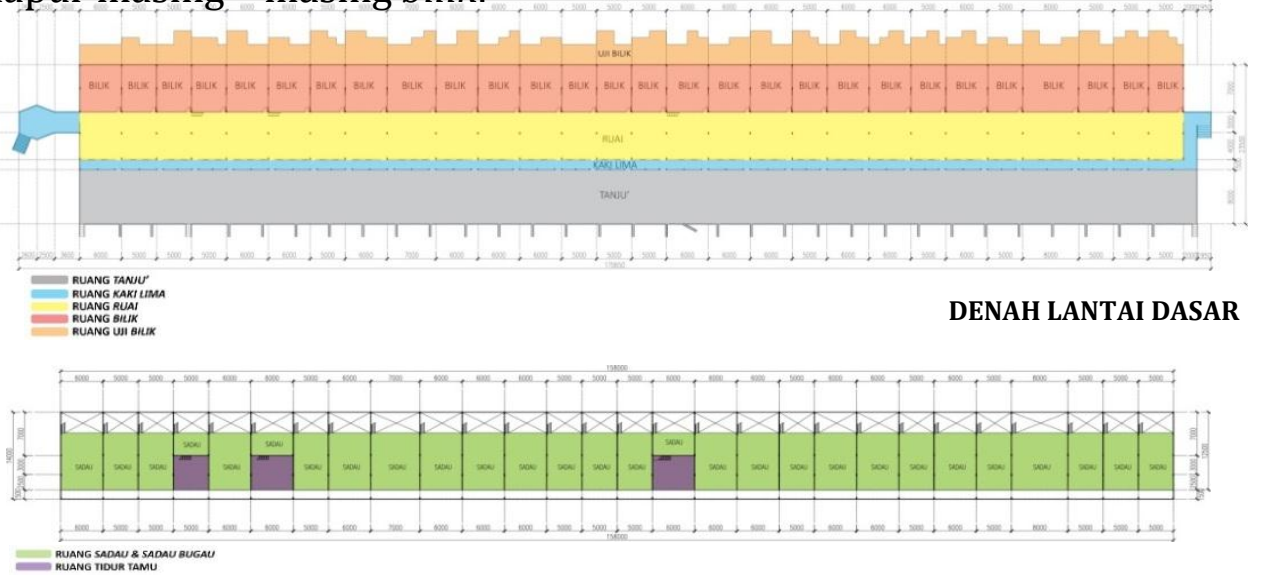

DENAH LANTAI ATAS/ATAP

Gambar 5. Denah setelah penambahan ruang pada Rumah Panjae Suku Dayak Iban 

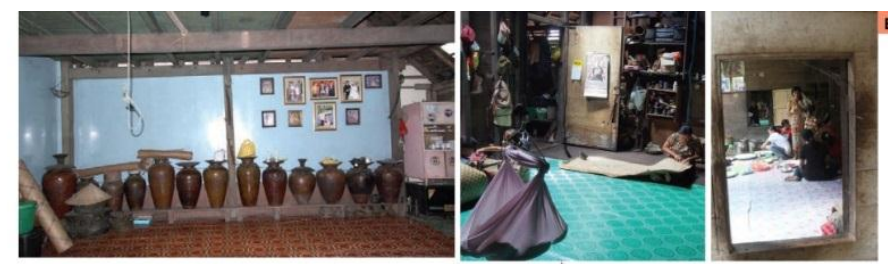

BILIK

Ruang bilik pada Rumah Panjae

(rumah panjang) Suku Dayak Iban Sungai Utik merupakan ruangan yang di huni secara

bersama - sama oleh beberapa keluarga turun temurun dari masyarakat Suku Dayak Iban.
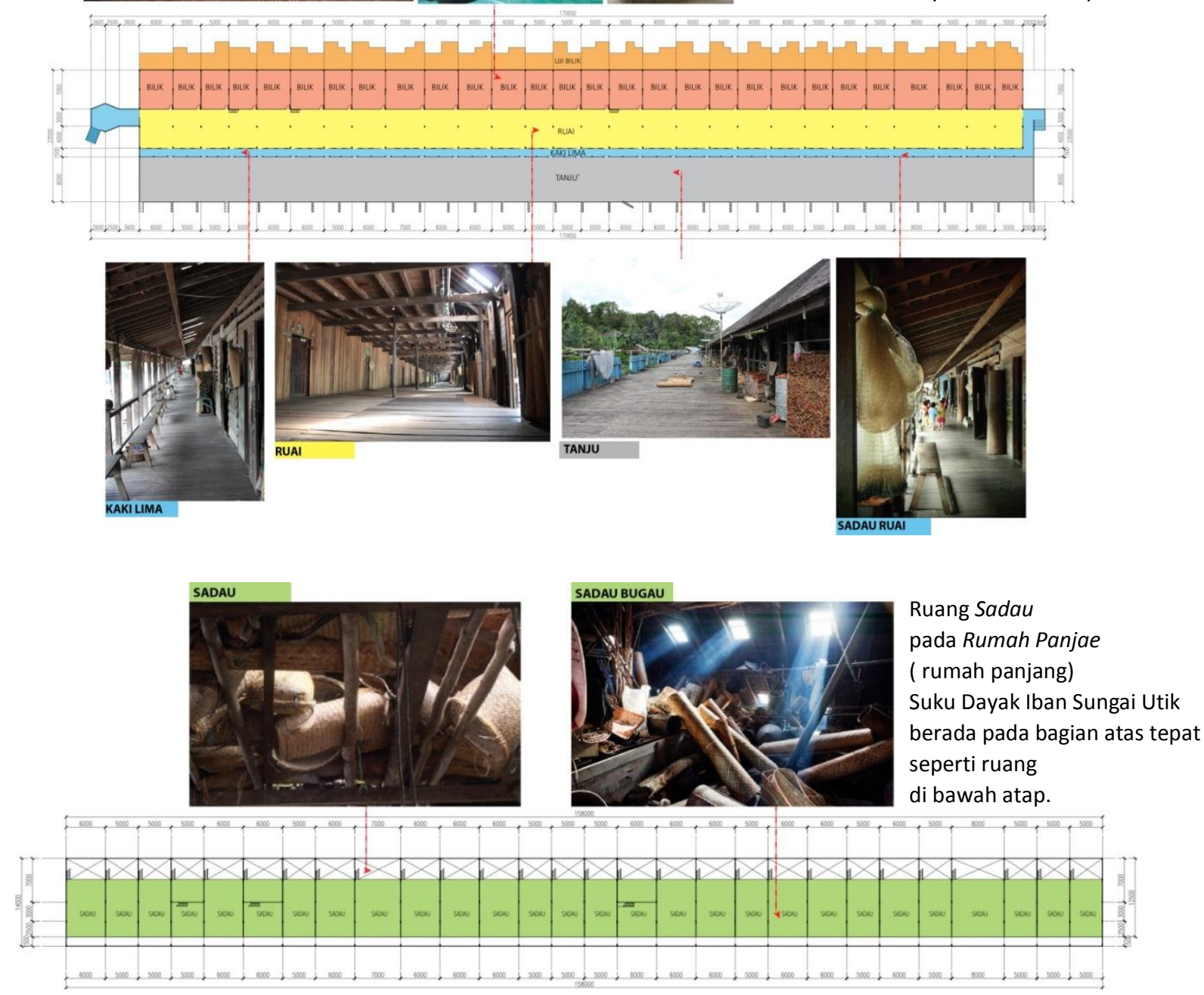

Gambar 6. Kondisi ruang pada Rumah Panjae Suku Dayak Iban

\subsection{Zoning Ruang Rumah Panjae Suku Dayak Iban Sungai Utik}

Zoning pada ruang Rumah Panjae sangat sederhana karena berfungsi sesuai kebutuhan saat itu, baik itu untuk menjemur hasil pertanian dan berkumpul, istirahat dan berkegiatan sehari - hari serta atas dasar kepercayaan masyarakat dari para leluhur mereka, terkadang di gunakan juga untuk ritual upacara adat tertentu, zona ruang yang terdapat didalam Rumah Panjae dilakukan berdasarkan pengelompokan kepercayaan akan orientasi matahari yang berarti pada bagian timur adalah kehidupan pada ruang bilik 
sedangkan pada ruang tanju' di arah barat yang berarti kematian. Pengelompokan tersebut dilakukan karena fungsi dari rumah itu sebagai tempat tinggal bersama, sehingga fungsional ruang pada Rumah Panjae dilakukan berdasarkan pengelompokan tersebut seperti Gambar yang menjelaskan bagaimana pengelompokan tersebut terjadi pada (Gambar 4.9).

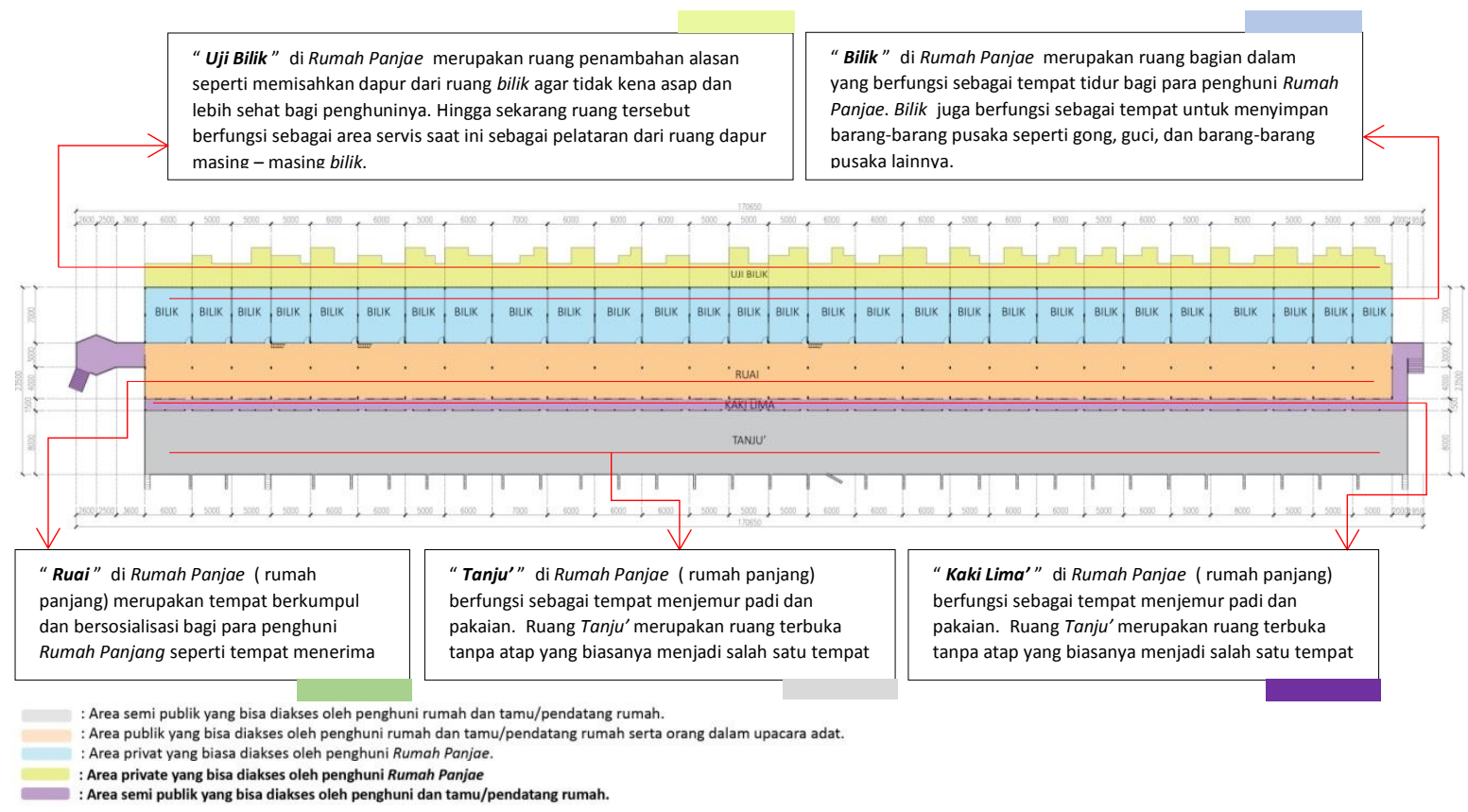

Gambar 7. Zoning ruang lantai dasar pada Rumah Panjae Suku Dayak Iban

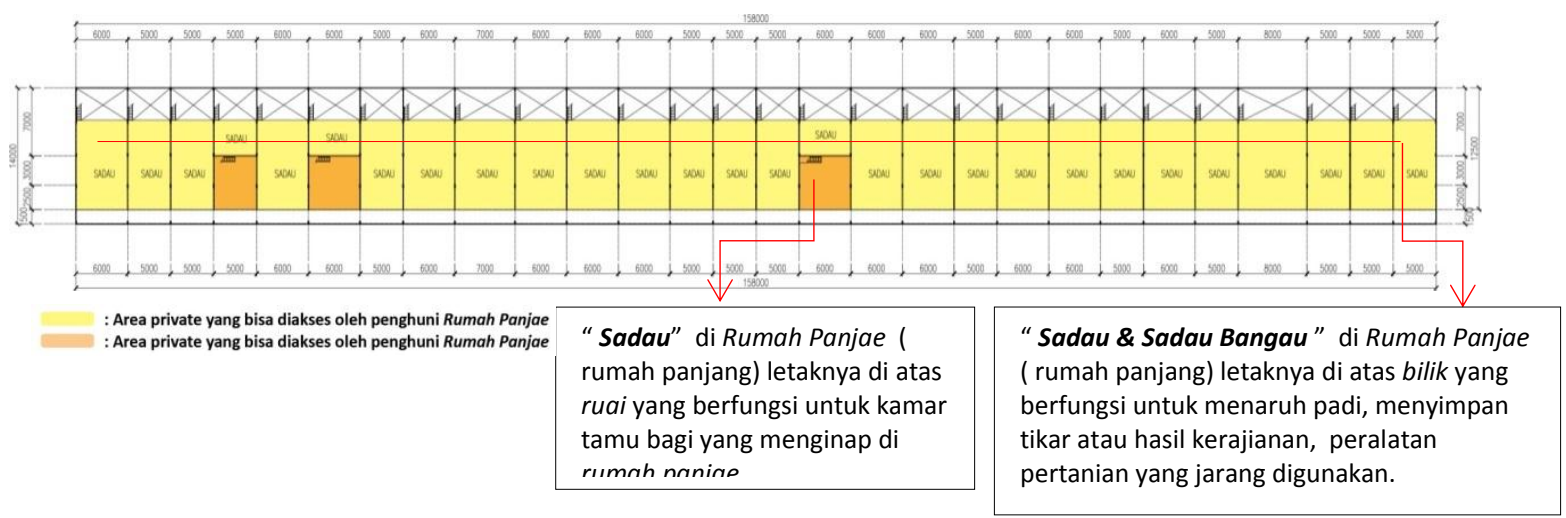

Gambar 8. Zoning ruang lantai atas pada Rumah Panjae Suku Dayak Iban

Berdasarkan pengelompokan fungsi yang ada dilihat dari munculnya ruang yang digunakan dan ditinjau dari status, dan perbedaan jenis kelamin. Ruang didalam satu rumah yang dapat dikelompokkan menjadi 3 fungsi, dikelompokkan berdasarkan status pernikahan, perbedaan jenis kelamin dan kepentingan ruangan yang digunakan yaitu; 
A. Publik, sebuah ruangan yang dapat di akses oleh penghuni atau tamu bagi Rumah Panjae yang dapat di bilang sebuah ruang yang sangat penting dalam sebuah rumah untuk besrsosialisasi baik itu saat ucpacara ritual adat tertentu atau pun kegiatan sehari-sehari yang berlangsung di rumah tersebut, dengan di batasi tertutup oleh dinding.

B. Semi Publik, ruangan yang berada di area luar atau tidak memiliki atap yang berfungsi sebagai ruang untuk menjemur baik itu menjemur hasil panen serta padi atau pun menjemur pakaian.

C. Privat, sebuah ruang yang berfungsi sebagai kegiatan dari tiap - tiap keluarga yang tinggal di rumah panjae dan sangat berbeda dari fungsi yang lainnya, yaitu karena ruang ini hanya bisa di akses oleh penghuni dari ruang tersebut.

\subsection{Hirarki Ruang Rumah Panjae Suku Dayak Iban Sungai Utik}

Transisi ruang-ruang pada Rumah Panjae ruang terpusat pada satu ruang yaitu ruang Ruai yang menjadi salah satu ruang inti keberlangsungan hidup pada Rumah Panjae. Ruai yang merupakan ruang pusat dan menghubungkan keruang yang ada dibelakangnya dan bagian terasnya. Pada bagian ruang Ruai sebagai ruang penghubung yang menjadi tempat untuk masyarakat penghuni rumah atau pun masyarakat yang berkunjung kerumah panjang baik itu dalam keseharian atau pun dalam kegiatan ritual upacara adat tertentu. Dalam pembentukan tersebut dapat di lihat pada gambar 4.11, yang merupakan gambaran tentang hirarki serta transisi ruang - ruang yang terdapat di rumah panjang. Hirarki ruang tersebut terbentuk karena kepercayaan dari masayarakat Iban akan hidup dalam kebersamaan yang selama ini para tetua mereka bangun.

Namun untuk memasuki Rumah Panjae hanya terdapat dua pintu masuk ke dalam rumah panja hal ini di sebabkan karena suku iban sering mengalami peperangan antar suku sehingga untuk memasuki rumah hanya ada dua akses karena untuk bertahan saat perang antar suku.

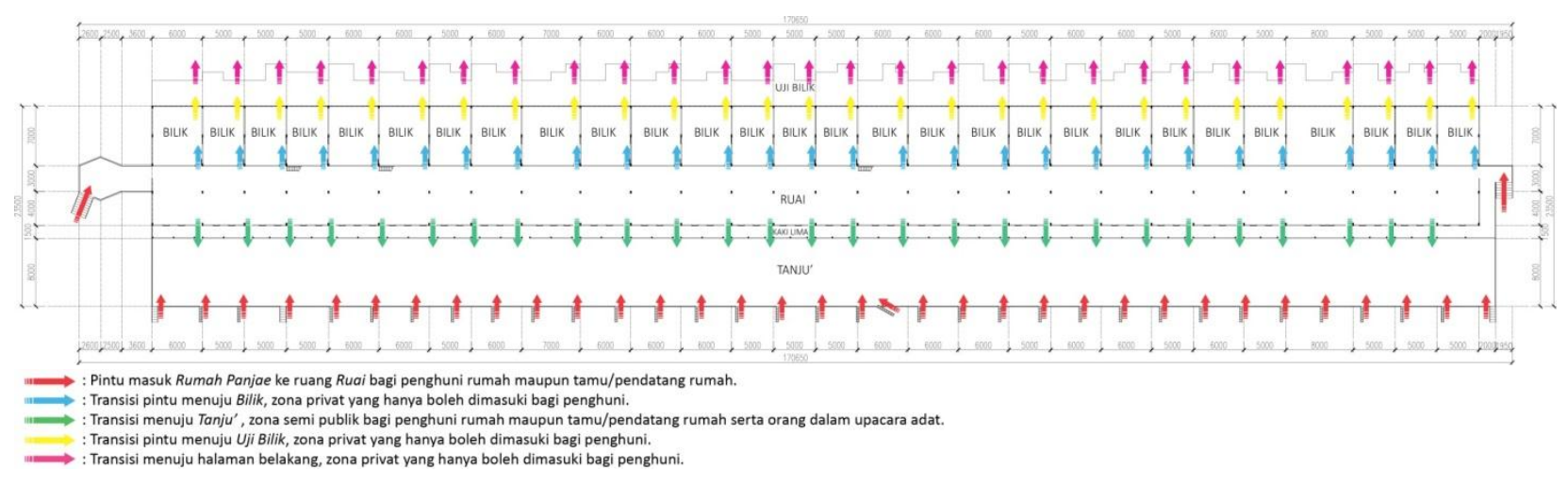

Gambar 9. Hirariki ruang lantai dasar pada Rumah Panjae Suku Dayak Iban 


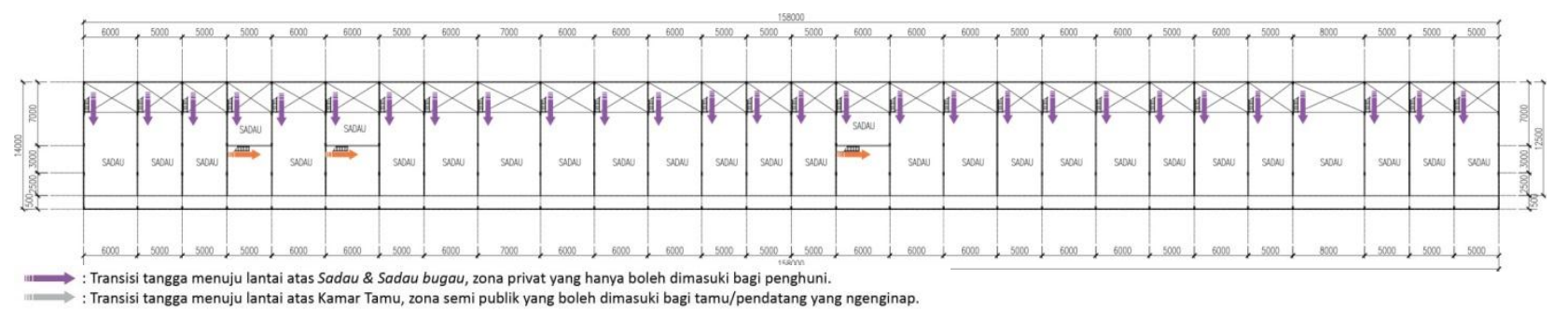

Gambar 10. Hirarki ruang lantai atas pada Rumah Panjae Suku Dayak Iban

\section{Kesimpulan}

Rumah Panjae Suku Dayak Iban Sungai Utik adalah salah satu Rumah Panjae di Provinsi Kalimantan Barat. Saat ini keberadaan Rumah Panjae tersebut masih di huni secara komunal hingga saat ini, namun masih banyak Rumah Panjang yang tidak terawat dan bahkan sudah ada yang tidak berdiri lagi. Bangunan Rumah Panjae Suku Dayak Iban Sungai Utik memiliki ruang dalam yang digunakan secara komunal oleh masyarakat Iban. Ruang yang membentuk linier pada Rumah Panjae Suku Dayak Iban Sungai Utik memiliki Ruai dan Bilik yang menjadi kamar tidur bagi penghuni. Penambahan ruang di Rumah Panjae terjadi karena kebutuhan dari masyarakat dan saat ini pembangunan untuk penambahan ruang Bilik juga tidak pernah di lakukan lagi karena alasan tertentu. Berdasarkan penambahan ruang Rumah Panjae Suku Dayak Iban Sungai Utik tidak terjadi perubahan bentuk dalam ruang - ruang yang asli karena penambahan ruang tidak terlalu banyak dan hanya terjadi pada sisi depan dan belakang ruang pada Rumah Panjae, sehingga terdapat ruang baru yaitu ruang Kaki Lima pada bagian depan \& Uji Bilik pada bagian belakang rumah

\section{Daftar Pustaka}

Kanyan S. Jacobus E. Frans L. dan Concordius,1998 Rumah panjang sebagai pusat kebudayaan pada masyarakat suku bangsa Dayak Iban, Jakarta: Grasindo

Proyek Seni Pulang. 2013. Tanah To Indai Kitae. Kalimantan Barat : Jaringan Arsip Budaya Nusantara.

Silas, J. 1983. Beberapa Pemikiran Dasar Tentang Perumahan dan Perkampungan di Indonesia, Makalah dalam Diskusi Ilmiah Mahasiswa Arsitektur Indonesia di Bandung. Bandung, 29 September 1983.

Turner, J.F.C., and Fitcher. 1972. Freedom to Build. Coller Macmillan: New York.

Triyanto. 2001. Makna Ruang dan Penataannya dalam Arsitektur Rumah Kudus, cet. Semarang: Kelompok Studi Mekar. 